Quim. Nova, Vol. 35, No. 2, 332-336, 2012

\title{
DEGRADAÇÃO FOTOELETROQUÍMICA DO HERBICIDA BENTAZONA SOBRE ELETRODOS DE CARBONO MODIFICADOS POR $\mathrm{TiO}_{2}$
}

\author{
Guilherme Garcia Bessegato \\ Universidade Tecnológica Federal do Paraná, Campus Toledo, Rua Cristo Rei, 19, 85902-490 Toledo - PR, Brasil \\ Valderi Pacheco Santos* e Cleber Antonio Lindino \\ Universidade Estadual do Oeste do Paraná, Campus Toledo, Rua da Faculdade, 645, 85903-000 Toledo - PR, Brasil
}

Recebido em 31/3/11; aceito em 8/8/11; publicado na web em 30/9/11

\begin{abstract}
PHOTOELECTROCHEMICAL DEGRADATION OF THE HERBICIDE BENTAZONE ON THE CARBON ELECTRODES MODIFIED BY $\mathrm{TiO}_{2}$. This work involved the study of degradation of the herbicide bentazone in aqueous solution by different routes, in order to search a method that generates safe products to the environment. It was tested electrochemical polarization methods involving positive and negative potential, irradiation with $\mathrm{UV}$ light and deposition of $\mathrm{TiO}_{2}$ on the electrode surface, seeking a catalytic effect. After different times of degradation, aliquots were removed and the scan of molecular absorption spectrum of UV-Vis was performed. From the spectra decay of bentazone, the kinetics of different processes was accompanied and the rate constants were determined.
\end{abstract}

Keywords: pesticides degradation; heterogeneous photocatalysis; $\mathrm{TiO}_{2}$ deposits.

\section{INTRODUÇÃO}

A água faz parte da grande maioria das atividades humanas e, por isso, é essencial à manutenção da vida no planeta. A maioria dos contaminantes químicos presentes em águas subterrâneas e superficiais está relacionada às fontes industriais e agrícolas. A variedade é enorme, com destaque para os agrotóxicos, os compostos orgânicos voláteis e os metais. ${ }^{1}$

O Brasil, desde a década de 70, destaca-se como um dos maiores consumidores mundiais de agrotóxicos, principalmente de herbicidas. ${ }^{2}$ Muitos desses herbicidas são altamente tóxicos, como é o caso do Basagran ${ }^{\circledR}$, que tem como ingrediente ativo a bentazona, do grupo químico das benzotiadiazinonas, sendo um herbicida pós-emergente seletivo às culturas de soja, arroz, feijão, milho e trigo, recomendado no controle de diversas plantas daninhas. ${ }^{3,4}$

A bentazona é um agroquímico da classe toxicológica I - extremamente tóxico e nocivo por ingestão e que pode causar sensibilização em contato com a pele. Em longo prazo, pode causar efeitos danosos ao ambiente aquático, sendo pertencente à classe ambiental III - perigoso ao meio ambiente, por ser altamente móvel, apresentando alto potencial de deslocamento no solo e podendo atingir principalmente as águas subterrâneas. Possui ainda característica de ser altamente persistente no meio ambiente, ou seja, de difícil degradação. ${ }^{4}$

A bentazona (2,2-dióxido de 3-isopropil(1H)-benzo-2,1,3-triadizin-4-ona), cuja estrutura química é mostrada abaixo, é pertencente ao grupo químico das benzotiadiazinonas.<smiles>CC(C)N1C(=O)c2ccccc2NS1(=O)=O</smiles>

Pesticidas lixiviados por águas de chuvas podem atingir a zona insaturada da coluna do solo ao serem transportados por gravidade/

*e-mail: vpacheco@uepg.br capilaridade até as águas subterrâneas. Enxurradas e erosões constituem fontes adicionais para facilitar contaminações de águas de rios. ${ }^{5}$

A dissipação da bentazona no solo é dependente de fenômenos como degradação por micro-organismos, lixiviação e escoamento superficial. Porém, essa molécula é moderadamente resistente à degradação $\left(\mathrm{t}_{1 / 2}=2\right.$ a 14 semanas) em solos minerais aeróbios. A baixa atenuação da toxicidade aliada à alta capacidade de lixiviação do pesticida, devido à sua baixa capacidade de adsorção em coloides do solo, resulta em fácil arraste aos mananciais e águas subterrâneas por enxurradas. ${ }^{6}$

Em ambientes aquáticos a degradação da bentazona parece depender da fotólise. Levando-se em conta que o pesticida apresenta um baixo coeficiente de adsorção no solo $(0,176$ a 3,056) e, também, considerando o fato de esse ser altamente solúvel em água, é inevitável que ocorra lixiviação e escoamento superficial. Devido a isso, a EPA identificou a existência de bentazona em águas subterrâneas nos estados da Virgínia, Missouri, Califórnia e, mais recentemente, na Flórida. ${ }^{6}$

O município de Toledo e demais municípios da região oeste do Paraná são fortes produtores de soja e milho, com característica predominante de monoculturas. Para melhoria de produtividade e diminuição de outros gastos, como mão-de-obra, é inevitável que sejam utilizados agrotóxicos para o controle de ervas daninhas que venham a prejudicar as plantações. O herbicida bentazona, seletivo às culturas predominantes da região, consta na lista de agrotóxicos de uso permitido no estado do Paraná e é o objeto central de estudo do presente trabalho.

Neste sentido, o principal objetivo deste trabalho foi promover a degradação do herbicida bentazona por meio de um método fotoeletroquímico, utilizando eletrodo de trabalho de carbono com modificação superficial por dióxido de titânio, visando o aumento da atividade catalítica do eletrodo a partir da combinação da polarização eletroquímica com o processo fotodegradativo.

Segundo a literatura, a eletrocatálise de oxidação de pequenas moléculas orgânicas em superfícies eletroativas modificadas por deposição de óxidos metálicos ocorre mediante um mecanismo bifuncional, segundo o qual o substrato favorece a adsorção da molécula orgânica e os óxidos metálicos atuam como sítios ativos que 
promovem a transferência de oxigênio para a degradação oxidativa da molécula em suas vizinhanças. ${ }^{7-9}$ Há, entretanto, estudos mais recentes que têm sugerido que superfícies metálicas compostas por mais de um elemento melhoram a atividade catalítica do eletrodo por meio de um efeito puramente de indução eletrônica, reduzindo a energia de interação da molécula orgânica com a superfície e favorecendo sua oxidação. ${ }^{10,11}$

\section{Fotocatálise}

A radiação ultravioleta (UV), quando utilizada sem ser conjugada a outros processos (tais como $\mathrm{O}_{2}, \mathrm{H}_{2} \mathrm{O}_{2}$ ) é chamada de fotólise, que é um sistema baseado numa interação irreversível da luz com a molécula, causando sua destruição total ou parcial. Outros processos fotodegradativos que vêm sendo muito utilizados são os processos oxidativos avançados (POA) baseados na geração de radicais hidroxila $(\mathrm{OH})$ pela exposição à irradiação UV. Estes, por sua vez, são agentes oxidantes poderosos $\left(\mathrm{E}_{\mathrm{o}}=+2,8 \mathrm{~V}\right.$ vs. $\left.E P H\right)$ produzidos no próprio meio reacional, de vida curta, que podem reagir com vários tipos de compostos orgânicos e inorgânicos e gerar como produtos finais $\mathrm{CO}_{2}$, água e ânions inorgânicos. Por isso, nos últimos anos têm-se dado ênfase aos POA, entre os quais merecem destaque a fotólise do $\mathrm{H}_{2} \mathrm{O}_{2}$, a reação foto-Fenton e a fotocatálise heterogênea com óxido de titânio. ${ }^{12}$

Diversos pesquisadores vêm utilizando os POA em tratamentos de diversos tipos de contaminantes. Vianna et al. ${ }^{13}$ reportam o uso de um POA com $\mathrm{TiO}_{2} / \mathrm{H}_{2} \mathrm{O}_{2} / \mathrm{UV}$ para a degradação de corantes ácidos empregados nas indústrias alimentícia, farmacêutica, de cosméticos e têxtil. Amorim et al. ${ }^{14}$ avaliaram a aplicabilidade de diferentes tecnologias avançadas de oxidação (combinação de peróxido, UV e $\mathrm{Fe}^{2+}$ ) na descoloração do corante do tipo azo Reactive Red 195, extensivamente utilizado nas indústrias têxteis brasileiras. $\mathrm{O}$ uso do processo foto-Fenton na degradação de componentes BTX tóxicos contidos em gasolinas foi estudado por Tiburtius et al..${ }^{15}$ Melo et al. ${ }^{16}$ apresentam resultados obtidos na aplicação de diferentes POA à degradação de fármacos de maior ocorrência em ambientes aquáticos e discutem a formação de intermediários de degradação e sua toxicidade.

Outros estudos demonstram a versatilidade da técnica de fotodegradação no tratamento de resíduos de pesticidas em águas e solos. Entre eles, Teixeira et al. ${ }^{17}$ analisaram a eficiência dos POA na remediação de águas residuais contaminadas por inseticidas e fungicidas e a influência da concentração de $\mathrm{Fe}^{2+}$ e peróxido, do $\mathrm{pH}$, da temperatura e da radiação no processo foto-Fenton. Estudos de degradação do pesticida clorado DDT em solo através da reação de Fenton foram realizados por Villa et al.. ${ }^{18}$

Chifu e Yunzhang ${ }^{3}$ estudaram o uso do pó de $\mathrm{TiO}_{2}$ como fotocatalisador na degradação do herbicida glifosato, controlando variáveis como $\mathrm{pH}$, temperatura e irradiação. Outro estudo semelhante foi realizado por Devipriya e Yesodharan, ${ }^{19}$ porém com pesticidas organoclorados. Eyheraguibel et al. ${ }^{20}$ estudaram a fotólise de três herbicidas via irradiação UV na vegetação, caracterizando a fotorreatividade sobre cera de carnaúba comercial.

A fotocatálise heterogênea é uma técnica que se baseia no uso de reagentes semicondutores, usados como catalisadores no processo de fotodegradação. Nesse caso, o melhor reagente é o dióxido de titânio $\left(\mathrm{TiO}_{2}\right)$, pois apresenta vantagens como sua não toxicidade e estabilidade química numa ampla faixa de $\mathrm{pH}$, boa capacidade de adsorção, além de baixo custo. No mecanismo de ação do $\mathrm{TiO}_{2}$ como catalisador no processo de fotocatálise heterogênea, proposto por Ziolli et al. ${ }^{21}$ e Melo et al. ${ }^{16}$ a irradiação do óxido metálico promove um estado eletronicamente excitado, no qual um elétron da banda de valência passa para a banda de condução, gerando um par elétron-vacância. O caráter oxidante da vacância da banda de valência gera radicais hidroxila $(\mathrm{OH})$ pela oxidação de moléculas de $\mathrm{H}_{2} \mathrm{O}$ adsorvidas na superfície do semicondutor. Esses radicais, por sua vez, desencadeiam reações radicalares de oxidação dos compostos em solução, processo chamado de mecanismo indireto de oxidação.

Apesar dos resultados promissores obtidos na fotodegradação de substâncias orgânicas utilizando o dióxido de titânio, a eficiência da fotocatálise está limitada pelo processo de recombinação de cargas do par elétron-vacância entre banda de condução e banda de valência, com dissipação de energia na forma de calor. Uma alternativa para minimizar a recombinação de cargas consiste em aplicar um potencial externo ao eletrodo de trabalho. O potencial aplicado provoca um gradiente de potencial para o interior do filme de $\mathrm{TiO}_{2}$, originando uma força que conduz elétrons e vacâncias fotogeradas em direções opostas e inibe a recombinação. ${ }^{22}$

Os semicondutores disponíveis para processos de fotocatálise heterogênea apresentam bandas de absorção no UV próximo (320$400 \mathrm{~nm}$ ), permitindo seu uso em aplicações solares. Para o $\mathrm{TiO}_{2}$, a energia de gap é de $3,2 \mathrm{eV}$, o que corresponde à radiação ultravioleta $(\lambda<380 \mathrm{~nm})$. Apesar da eficiência na mineralização de inúmeras espécies químicas de relevância ambiental, existem inconvenientes de ordem prática que dificultam o tratamento em larga escala, como dificuldade de penetração da irradiação no meio reacional e separação dos catalisadores que são utilizados na forma de finas suspensões. ${ }^{16}$

Dessa maneira, a deposição do óxido metálico na superfície de um eletrodo elimina o inconveniente de separação do catalisador em suspensão na água. Além disso, a aplicação de potencial eletroquímico faz com que não seja necessária a adição de outros reagentes, como o próprio peróxido de hidrogênio ou outros aceptores de elétrons, uma vez que a aplicação de potencial positivo junto com a irradiação UV promove um efeito sinérgico entre a polarização eletroquímica e a fotodegradação.

\section{PARTE EXPERIMENTAL}

A partir do Basagran ${ }^{\circledR} 600$ (solução comercial 60,0\% m/v, de procedência Basf) preparou-se uma solução na concentração de 1,0 x $10^{-5} \mathrm{~mol} \mathrm{~L}^{-1}$ em meio de $\mathrm{H}_{3} \mathrm{PO}_{4} 0,01 \mathrm{~mol} \mathrm{~L}^{-1}$. Esta concentração foi utilizada em todos os ensaios.

Para os ensaios eletroquímicos, utilizou-se a técnica de cronoamperometria com um potenciostato Microquímica ${ }^{\circledR}$ PG-01, em célula eletroquímica com eletrodo de trabalho de carbono, eletrodo de referência de $\mathrm{Ag} / \mathrm{AgCl}$ e eletrodo auxiliar de platina. As medidas foram realizadas à temperatura ambiente.

Quanto aos ensaios fotoquímicos, a degradação foi realizada em uma câmara de irradiação com lâmpada UV de $80 \mathrm{~W}$.

Em todos os testes (fotoquímicos ou eletroquímicos), após determinados tempos de degradação (até um limite de $90 \mathrm{~min}$ ), foram retiradas alíquotas da solução e realizou-se a varredura do espectro de absorção UV-Vis em um espectrofotômetro de feixe duplo de marca Shimadzu ${ }^{\circledR}$ PC 1600 , entre 400 e $200 \mathrm{~nm}$.

Primeiramente foram realizados os ensaios somente eletroquímicos. Em princípio, foi realizado um estudo com polarização em potencial negativo $(-0,55 \mathrm{~V}) \mathrm{e}$, posteriormente, com polarização em potencial positivo $(+1,0 \mathrm{~V})$. Em uma próxima etapa, testou-se a estabilidade da molécula de bentazona frente à degradação fotoquímica sem aplicação de potencial eletroquímico, deixando-se a solução de Basagran ${ }^{\circledR}$ exposta à irradiação UV durante períodos de tempo determinados. Posteriormente testou-se a degradação fotoeletroquímica, aplicando-se potencial positivo $(+1,0 \mathrm{~V})$ na célula de irradiação. Também se realizou a degradação fotoeletroquímica com polarização em potencial negativo $(-0,55 \mathrm{~V})$.

Depois destes testes, fez-se a deposição da superfície catalítica de $\mathrm{TiO}_{2}$ no eletrodo de carbono a partir de solução de cloreto de 
titânio (III) a 1,5\% em $\mathrm{H}_{3} \mathrm{PO}_{4} 0,01 \mathrm{~mol} \mathrm{~L}{ }^{-1}$. Registraram-se ciclos voltamétricos entre os potenciais $0,45 \mathrm{e}-0,55 \mathrm{~V}$ durante 100 ciclos para deposição do óxido metálico.

Testou-se então a degradação fotoeletroquímica da bentazona, colocando-se a solução sob irradiação UV paralelamente à polarização em $+0,5 \mathrm{~V}$ sobre o eletrodo de carbono com depósito de dióxido de titânio.

\section{RESULTADOS E DISCUSSÃO}

\section{Polarização eletroquímica}

O primeiro teste foi a polarização em potencial negativo da bentazona, que foi realizada em $-0,55 \mathrm{~V}$. Já o ensaio de polarização em potencial positivo foi realizado a $1,0 \mathrm{~V}$. Os espectros obtidos estão nas Figura 1a e 1b, respectivamente.
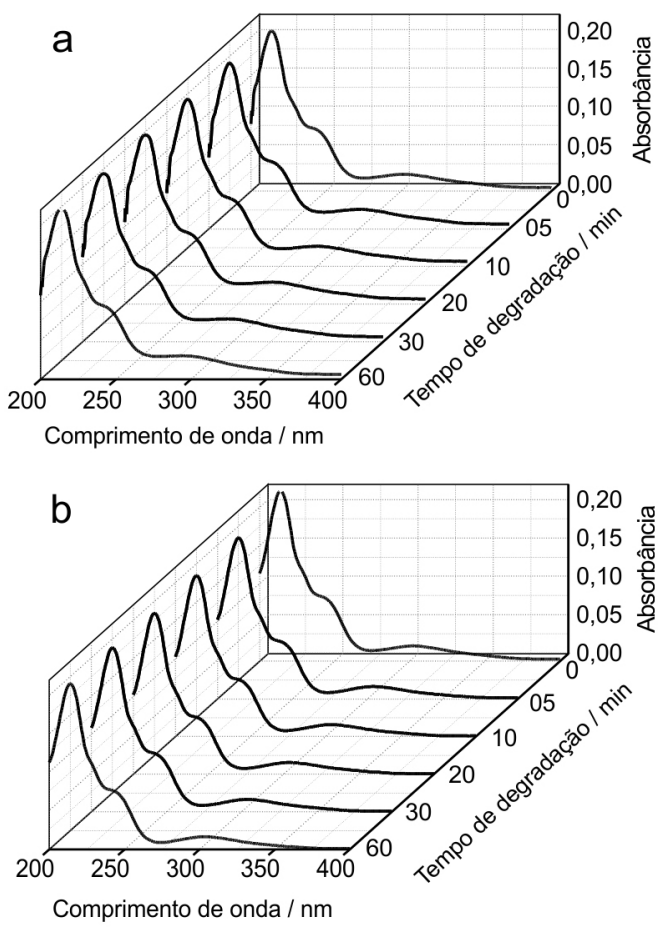

Figura 1. (a) Espectros de absorção da bentazona durante polarização em potencial negativo $(-0,55 \mathrm{~V})$ em eletrodo de carbono; (b) espectros de absorção da bentazona durante polarização em potencial positivo $(+1,0 \mathrm{~V})$ em eletrodo de carbono

De acordo com os espectros de absorção da Figura 1a, não há alteração significativa no perfil espectral da bentazona, mesmo após um tempo longo de polarização eletroquímica em potencial negativo, mas apenas um leve acréscimo na absorção. Após polarização positiva (Figura 1b), novamente pode-se perceber que não há alteração significativa no perfil espectral da bentazona. Estes são indicativos de que a polarização eletroquímica, dentro da faixa de potencial estudada, seja ela negativa ou positiva, não é suficiente para provocar por si só algum processo de degradação da molécula de bentazona.

\section{Degradação fotoquímica}

A degradação fotoquímica foi realizada em uma câmara com radiação UV incidindo verticalmente sobre a solução, sem aplicação de potencial eletroquímico. Os espectros resultantes são apresentados na Figura 2.

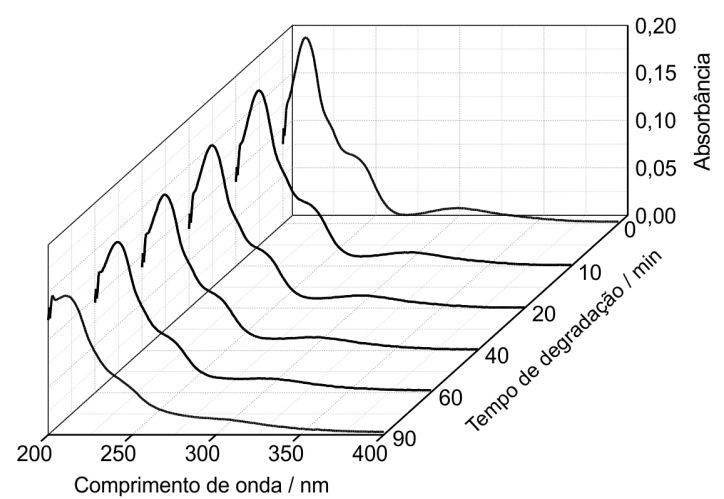

Figura 2. Espectros de absorção da bentazona sob exposição à luz UV sem aplicação de potencial

Observa-se claramente nos espectros uma diminuição gradativa do principal pico da bentazona (em $214 \mathrm{~nm}$ ), dando indício de um processo de degradação fotoquímica da molécula, diferentemente do que se observou na polarização somente eletroquímica.

\section{Degradação fotoeletroquímica}

Os espectros de absorção do Basagran ${ }^{\circledR}$, resultantes da degradação fotoeletroquímica em potencial de $-0,55 \mathrm{~V}$ e irradiação UV, são apresentados na Figura 3. Nos espectros, percebe-se que já nos primeiros minutos de ensaio há um aumento significativo no perfil de absorção em toda a faixa de comprimentos de onda estudada, o qual permanece alto até um tempo de $30 \mathrm{~min}$. Após esse período, há um decréscimo da absorção e o pico em $214 \mathrm{~nm}$ tende a diminuir pouco.

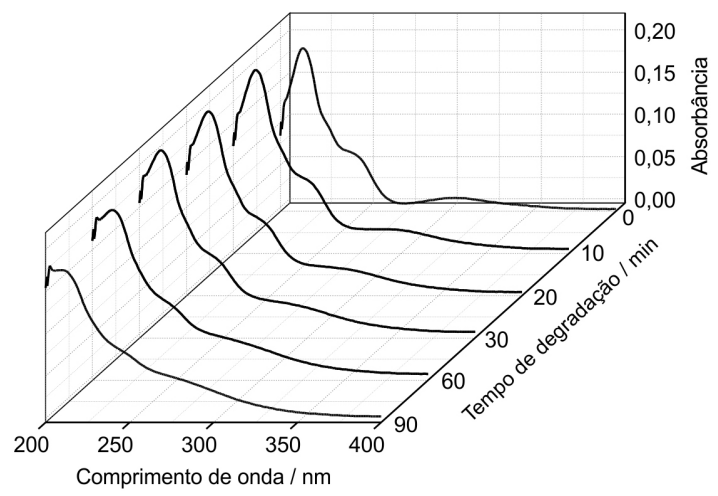

Figura 3. Espectros de absorção da bentazona sob exposição à luz UV e aplicação de potencial negativo $(-0,55 \mathrm{~V})$ em eletrodo de carbono

Esses perfis espectrais da bentazona, diferentes dos obtidos em todos os outros ensaios realizados no presente trabalho, sugerem que inicialmente há uma alteração química na molécula como consequência da combinação entre a polarização em potencial negativo e a irradiação com UV, o que provoca o aumento significativo de absorção em toda a faixa do espectro. Entretanto, só é possível afirmar que a espécie intermediária formada durante a polarização negativa retarda o processo de fotodegradação, ao contrário do que ocorre durante a degradação fotoeletroquímica com polarização positiva, analisada a seguir.

Os espectros obtidos após degradação fotoeletroquímica em potencial positivo de 1,0 V durante irradiação são dados na Figura 4. Diferentemente do ensaio fotoeletroquímico em potencial negativo, no ensaio em potencial positivo a bentazona não teve seu perfil de absorção drasticamente alterado entre 250 e 350 nm, porém, a 
polarização positiva se mostrou mais eficiente no processo de fotodegradação que a polarização negativa, o que pode ser confirmado no rápido decréscimo do perfil de absorção do espectro da bentazona após os primeiros $10 \mathrm{~min}$. Isto porque, enquanto a polarização negativa age no sentido de injetar elétrons na molécula, a polarização positiva retira elétrons da mesma, somando-se ao processo fotodegradativo, que é essencialmente um processo oxidativo.

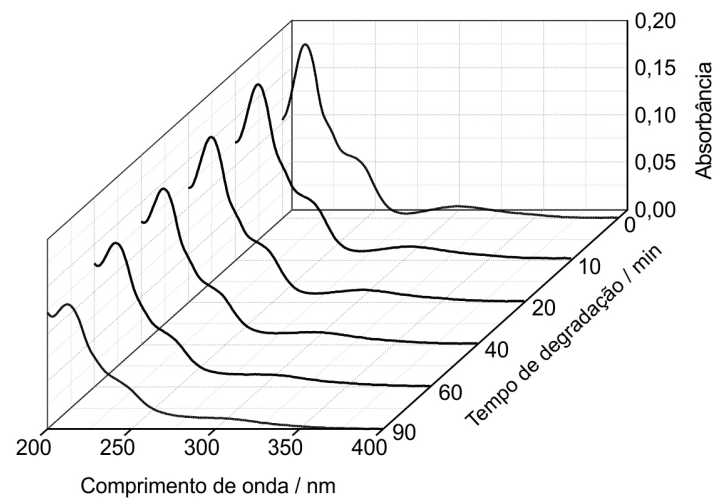

Figura 4. Espectros de absorção da bentazona sob exposição à luz UV e aplicação de potencial positivo $(+1,0 \mathrm{~V})$ em eletrodo de carbono

Ainda que a polarização somente eletroquímica não tenha se mostrado eficaz na degradação da bentazona, como demonstrado na Figura 1, os resultados da degradação fotoeletroquímica sugerem que a polarização eletroquímica age no sentido de favorecer a fotodegradação quando o potencial for positivo e de dificultar a fotodegradação quando o potencial for negativo.

\section{Deposição de $\mathrm{TiO}_{2}$}

A Figura 5 mostra os voltamogramas cíclicos de deposição do titânio sobre o eletrodo de carbono, nos quais é possível observar que com o acréscimo no número de ciclos se aumenta a quantidade dos depósitos de titânio na superfície. Isto é evidenciado principalmente devido ao acréscimo nas cargas catódicas abaixo de $-0,2 \mathrm{~V}$ (vs. $\mathrm{Ag} / \mathrm{AgCl}$ ), atribuído à formação de hidrogênio sobre o eletrodo. No eletrodo de carbono, o desprendimento de hidrogênio só ocorre em potenciais abaixo de $-0,6 \mathrm{~V}$, enquanto em eletrodos metálicos ou de óxidos metálicos, este processo ocorre por volta de $-0,2 \mathrm{~V}$ (vs. $\mathrm{Ag} / \mathrm{AgCl}$ ). Assim, o aumento do grau de recobrimento dos depósitos de titânio, além de favorecer a formação de hidrogênio, aumenta a rugosidade do eletrodo, aumentando as cargas de redução de hidrogênio.

$\mathrm{E} / \mathrm{V}$

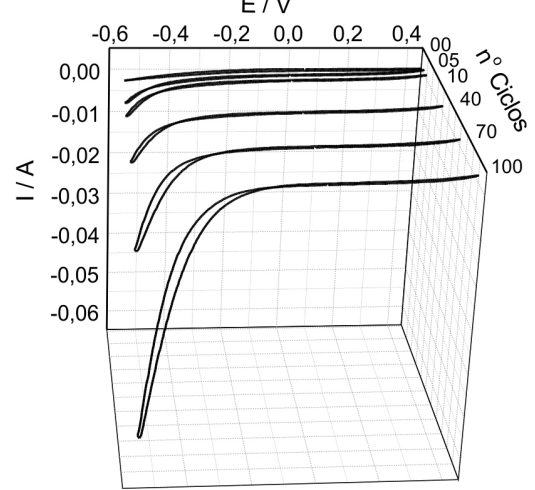

Figura 5. Voltamogramas cíclicos do eletrodo de carbono durante deposição da superfície catalítica de óxido de titânio (entre $+0,45 e-0,55 \mathrm{~V})$

\section{Degradação fotoeletroquímica sobre $\mathrm{C}-\mathrm{TiO}_{2}$}

A degradação fotoeletroquímica sobre o eletrodo modificado com $\mathrm{TiO}_{2}$ apresentou-se mais efetiva que nos ensaios utilizando somente irradiação UV ou com irradiação UV e polarização eletroquímica sobre carbono, mesmo em tempos mais curtos de degradação, como pode ser observado nos espectros da Figura 6.

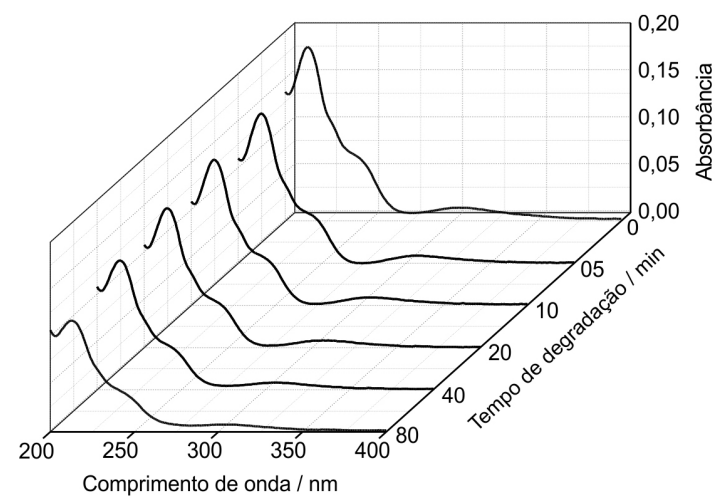

Figura 6. Espectros de absorção da bentazona sob exposição à luz UV e aplicação de potencial positivo $(+0,5 \mathrm{~V})$ em eletrodo de carbono modificado com $\mathrm{TiO}_{2}$

No caso do eletrodo modificado, a aplicação de potencial positivo e a presença de óxido de titânio favorecem ainda mais a retirada de elétrons da molécula, facilitando o processo de fotodegradação. Isto pode ser confirmado no rápido decréscimo dos picos e perda do perfil de absorção do espectro de UV-Vis da bentazona após $90 \mathrm{~min}$.

A oxidação da molécula de bentazona ocorre principalmente por um mecanismo de fotocatálise heterogênea, ${ }^{16} \mathrm{em}$ que, devido à alta reatividade dos radicais hidroxila formados e seu curto tempo de vida, provavelmente a degradação da bentazona pela via fotoeletrocatalítica ocorra somente na dupla camada, pois os radicais dificilmente irão se difundir até o seio da solução.

\section{Avaliação da cinética de decaimento espectral}

As curvas de decaimento espectral da bentazona em função do tempo de degradação foram registradas considerando-se que o processo segue um modelo de pseudoprimeira ordem, segundo a Equação 1, levando-se em consideração que durante a degradação somente a concentração da bentazona sofre alteração. Os outros fatores que influenciam na velocidade do processo, como concentração de fótons da fonte irradiadora e concentração do catalisador na superfície do eletrodo, não variam ao longo do processo, bem como não há formação de outra espécie que absorva de forma significativa na mesma faixa de comprimento de onda que a original, podendo-se atribuir o decaimento do pico em $214 \mathrm{~nm}$ somente à diminuição da concentração de bentazona.

$$
\ln \left(\frac{I}{I_{0}}\right)=-k \cdot t
$$

Assim, com os valores de máximo do pico em cada espectro, após diferentes tempos de degradação, em relação ao máximo do pico antes da degradação, calcula-se $\ln \left(\mathrm{I} / \mathrm{I}_{0}\right)$. As curvas de decaimento espectral obtidas para os diferentes métodos de degradação testados são mostradas na Figura 7, nas quais se pode perceber uma diferença significativa nas constantes de velocidade a partir dos diferentes coeficientes angulares das curvas:

- a degradação fotoeletroquímica com o eletrodo modificado com 
$\mathrm{TiO}_{2}$ apresentou a curva com maior inclinação e, portanto, ocorre com maior velocidade, confirmando a eficiência da fotocatálise heterogênea dos depósitos de $\mathrm{TiO}_{2}$ sobre o processo degradativo;

- a segunda maior inclinação, promovida pela degradação fotoeletroquímica em potencial positivo sobre o eletrodo de carbono, deve-se ao fato de o potencial positivo atuar juntamente com a irradiação UV na retirada de elétrons da molécula de bentazona. Assim, em relação à degradação fotoquímica, a fotoeletroquímica apresenta uma velocidade de decaimento maior, provavelmente devido ao efeito sinérgico entre a polarização eletroquímica positiva e o processo fotodegradativo;

- já a degradação fotoeletroquímica com polarização negativa foi a menos eficaz entre os processos estudados. No entanto, o processo não pode ser considerado como um decaimento cinético de primeira ordem, devido à provável formação de um intermediário de reação com forte absorção na mesma região espectral da bentazona e com maior tolerância ao processo de fotodegradação, sendo apresentado apenas com o intuito de comparar seu perfil discrepante e pouco eficaz de decaimento degradativo em relação aos demais processos.

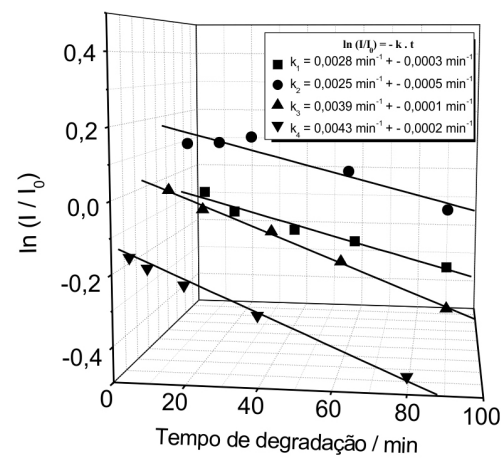

Figura 7. Curvas de decaimento e constantes de velocidade para os diferentes métodos de degradação da bentazona empregados: $k_{1}$ (degradação fotoquímica), $k_{2}$ (degradação fotoeletroquímica em potencial negativo), $k_{3}$ (degradação fotoeletroquímica em potencial positivo), $k_{4}$ (degradação fotoeletroquímica em potencial positivo sobre $\mathrm{C}-\mathrm{TiO}_{2}$

\section{CONCLUSÃO}

O processo de polarização eletroquímica, seja por aplicação de potencial positivo ou negativo, pouco influencia no comportamento espectral da bentazona. Já a degradação fotoquímica sob irradiação UV apresenta uma boa eficiência, que fica ainda mais pronunciada quando combinada à polarização eletroquímica em potencial positivo. Isto porque a polarização positiva força a retirada de elétrons da molécula, somando-se ao processo fotodegradativo, que é essencialmente um processo oxidativo. Por outro lado, a polarização em potencial negativo durante a irradiação não produz bom resultado, devido a um efeito contrário.

Por fim, o método de degradação mais eficiente entre os que foram estudados é o fotoeletroquímico em potencial positivo sobre o eletrodo de carbono após deposição de dióxido de titânio. Tal resultado se deve provavelmente a um processo da fotocatálise heterogênea sobre o $\mathrm{TiO}_{2}$ com contribuição da polarização eletroquímica.

\section{REFERÊNCIAS}

1. Fernandes Neto, M. L.; Sarcinelli, P. N.; Engenharia Sanitária Ambiental 2009, 14, 69.

2. Primel, E. G.; Zanella, R.; Kurz, M. H. S.; Gonçalves, F. F.; Machado, S. de O.; Marchezan, E.; Quim. Nova 2005, 28, 605.

3. Chifu, C.; Yunzhang, L.; Chemosphere 2007, 67, 1010.

4. Basf Portuguesa; Ficha de dados de segurança Basagran ${ }^{\circledR}$, Basf: Lisboa, 2002.

5. Rocha, J. C.; Rosa, A. H.; Cardoso, A. A.; Introdução à química ambiental, Bookman: Porto Alegre, 2004.

6. Abreu, C. F. V.; Dissertação de Mestrado, Universidade Nova de Lisboa, Portugal, 2008.

7. Janssen, M. M. P.; Moolhuysen, J.; Electrochim. Acta 1976, $21,869$.

8. Watanabe, M.; Motoo, S.; J. Electroanal. Chem. 1975, 60, 267.

9. Gasteiger, H. A.; Markovic, N.; Ross, P. N.; Cairns, E. J.; J. Phys. Chem. 1993, 97, 12020.

10. Christoffersen, E.; Liu, P.; Ruban, A.; Skriver, H. L.; Norskov, J. K.; J. Catal. 2011, 199, 123.

11. Babu, P. K.; Kim, H. S.; Oldfield, E.; Wieckowski, A.; J. Phys. Chem. B 2003, 107, 7595.

12. Nogueira, R. F. P.; Trovó, A. G.; da Silva, M. R. A.; Villa, R. D.; de Oliveira, M. C.; Quim. Nova 2007, 30, 400.

13. Vianna, V. B.; Torres, A. R.; Azevedo, E. B.; Quim. Nova 2008, $31,1353$.

14. Amorim, C. C.; Leão, M. M. D.; Moreira, R. F. P. M.; Engenharia Sanitária Ambiental 2009, 14, 543.

15. Tiburtius, E. R. L.; Peralta-Zamora, P.; Emmel, A.; Leal, E. S.; Quim. Nova 2005, 28, 61.

16. Melo, S. A. S.; Trovó, A. G.; Bautitz, I. R.; Nogueira, R. F. P.; Quim. Nova 2009, 32, 188.

17. Teixeira, A. C. S. C.; Mendes, L.; Stollar, G.; Guardani, R.; Nascimento, C. A. O.; Brazilian Archives of Biology and Technology 2005, 48, 207.

18. Villa, R. D.; Nogueira, R. F. P.; Eclética Química 2005, 30, 69.

19. Devipriya, S.; Yesodharan, S.; Sol. Energy Mater. Sol. Cells 2005, 86, 309.

20. Eyheraguibel, B.; Halle, A. T.; Richard, C.; J. Agric. Food Chem. 2009, 57, 1960.

21. Ziolli, R. L; Jardim, W. F.; Quim. Nova 1998, 21, 319.

22. Oliveira, H. G.; Dissertação de Mestrado, Universidade Estadual de Campinas, Brasil, 2008. 